\title{
Chemical Modification of Cellulosic Fibers Using Eco-Friendly Compounds to Improve Dyeing with Cationic Dyes
}

\author{
Feriel Bouatay*, Nizar Meksi, Fatma Slah and Mohamed FM
}

Research Unit of Applied Chemistry and Environment, Faculty of Sciences, Monastir University, Tunisia

\begin{abstract}
In order to improve their affinity to the cationic dyes, cotton and jute cellulosic fibres were chemically modified using natural compounds such as: Tannic acid, Mimosa and cactus juice and commercialized compounds such as Clarite Com, Albatex and Albaflow. Cellulose modifications were performed using physiochemical analysis such as Bohem titration, spectroscopic analysis (FTIR spectroscopy and UV-Vis), the Point of Zero Charge (pHPZC) and the Cationic Exchange Capacity (CEC) determination.

The dyeing performance were evaluated by controlling the percentage of the dye bath exhaustion ( $E$ \%), the color yield $(\mathrm{k} / \mathrm{s})$, the brightness index $\mathrm{BI}(\%)$ and the dyeing fastness to light, washing and rubbing.

Two cationic dyes $\mathrm{Cl}$ Basic Red 46 and $\mathrm{Cl}$ Basic Blue 3 with a delocalised cationic charge were checked for dyeing properties. The pHPZC of modified samples varied from 2.98 to 5.7 . The CEC varied from $43 \mathrm{meq} / \mathrm{g}$ to $82 \mathrm{meq} / \mathrm{g}$. This study showed that the color yield and the dyeing fastness were improved for modified cellulosic fabrics. The Bohem titration and FTIR spectrum showed that the acidic sites number on the fabrics increased after using anionic agents.
\end{abstract}

Keywords: Modified cellulosic fibres; Characterization; Cationic dyes; Dyeing affinity; Fastness properties

\section{Introduction}

Synthetic dyes have been widely used in comparison to natural dyes because of their lower prices, repeatability and wide range of bright shades with considerably improved color fastness properties [1]. Moreover, basic dyes are a group of water-soluble dyes which are employed in leather, paper preparing, printing and textile fibres dyeing. Their principle use is the dyeing of acrylics [2]. Furthermore, cationic dyes are available as cheap synthetic dyes amongst the commercial dye range. But, they are still the brightest and the most brilliant and presented the highest vivacity in hue of the synthetics dyes (Basic dyestuffs 1951).

In current practice, cotton fabrics are the widely used because they presented excellent physical and chemical properties in terms of water absorbency, dye ability and stability [3]. However, cationic dyes have very low substantivity for cellulosic fibres unless excessive oxidation has generated anionic carboxylate groups. In this regard, cellulosic fabrics were usually mordanted with tannic acid fixed with tartar emetic [4].

So that, the present study focuses on developing new dyeing processes to improve the dye ability and the fastness properties of the cotton and jute fabrics by cationic dyes. Indeed, few researches look for a solution to enhance dye-fibres interactions via pre-treatment using tannins [5] or chemical surface modification [6]. Nevertheless, basic dyes have no direct affinity for cellulose. But jute fibers processes good affinity due to the presence of the lignin (12-15\%) and hemicelluloses. Despite of their high tinctorial power, it has been observed that, during practice, they possess very poor light fastness [6].

In the present paper, to improve dyeing quality of cotton and jute fibres on the cationic dyes, cellulosic fabrics modifications by ecofriendly and chemical processes were developed. Surface modifications by natural and chemical products were performed on studied samples. Indeed, physiochemical analysis such as Bohem titration, spectroscopic analysis (FTIR spectroscopy and UV-Vis) and the Point of Zero Charge (pHPZC) and the Cation Exchange Capacity (CEC) were investigated before and after using of modification agents. Moreover to evaluate and compare the dyeing quality, colour yield (K/S), extent of exhaustion, Brightness Index as well as the CIELab coordinates and the corresponding fastness properties were determined after dyeing process on modified samples.

\section{Experimental}

\section{Textile materials}

Commercially cotton fabric with the following specifications was used: plain weave; ends per $\mathrm{cm}, 33.02$; picks per $\mathrm{cm}, 38.1$; warp count, 10.5; weft count, 15; weight, $245 \mathrm{gm}^{-2}$. It was bleached firstly with a solution containing $4 \mathrm{ml} / \mathrm{L}$ of sodium silicate, $4 \mathrm{ml} / \mathrm{L}$ of sodium hydroxide $\left(36^{\circ} \mathrm{Be}\right)$ and $15 \mathrm{ml} / \mathrm{L}$ of hydrogen peroxide kept to liquor ration $40: 1$ at $70^{\circ} \mathrm{C}$ for 60 minutes. Then, samples were neutralized with $1 \mathrm{ml} / \mathrm{L}$ of Acetic acid. Finally, the bleached cotton samples were washed thoroughly with cold water and dried.

Jute fabric was procured commercially and has with the following specifications: plain weave; ends per cm, 33.02; picks per cm, 38.1; warp count, 10.5; weft count, 15 ; weight, $440 \mathrm{gm}^{-2}$. It was bleached firstly with a solution containing $35 \mathrm{ml} / \mathrm{L}$ of sodium hypochlorite, $3 \mathrm{~g} / \mathrm{L}$ of sodium carbonate kept to liquor ration $40: 1$ at room temperature $\left(20^{\circ} \mathrm{C}\right)$ for 50 minutes. Thenanti-chlorine treatment was realized in a solution containing $0.5 \mathrm{ml} / \mathrm{L}$ of hydrochloric acid and $1 \mathrm{~g} / \mathrm{L}$ of sodium bisulfite

${ }^{*}$ Corresponding author: Feriel Bouatay, Research Unit of Applied Chemistry and Environment, Faculty of Sciences, Monastir University, Tunisia, Tel: +21673-462-853; E-mail: bouatay_feriel@hotmail.com

Received January 22, 2014; Accepted January 29, 2014; Published February 02, 2014

Citation: Bouatay F, Meksi N Slah F, Mohamed FM (2014) Chemical Modification of Cellulosic Fibers Using Eco-Friendly Compounds to Improve Dyeing with Cationic Dyes. J Textile Sci Eng 4: 153. doi:10.4172/2165-8064.1000153

Copyright: (c) 2014 Bouatay F, et al. This is an open-access article distributed under the terms of the Creative Commons Attribution License, which permits unrestricted use, distribution, and reproduction in any medium, provided the original author and source are credited. 
Citation: Bouatay F, Meksi N, Slah F, Mohamed FM (2014) Chemical Modification of Cellulosic Fibers Using Eco-Friendly Compounds to Improve Dyeing with Cationic Dyes. J Textile Sci Eng 4: 153. doi:10.4172/2165-8064.1000153

at a liquor ration 40:1 at room temperature for 10 minutes. Finally, the bleached samples were washed thoroughly with cold water and dried.

\section{Chemicals}

The cationic dyes used (CI Basic Red 46, CI Basic Blue 3) are commercial dyestuffs. These basic dyes are supplied respectively by Ciba and DyStar companies. The molecular weight of these dyes are respectively $\mathrm{Mr}=432 \mathrm{~g} / \mathrm{mol}$ and $\mathrm{Mr}=359.45 \mathrm{~g} / \mathrm{mol}$. The molecular structures are shown in Figure 1. The UV-vis spectra of the dyestuffs aqueous fraction were recorded using a CECIL 2021 Instruments UV/ Vis spectrophotometer and the results are represented in Figure 2.

The maximum wavelengths $\lambda$ max of the CI BR 46 and CI BB3 were found to be respectively $530 \mathrm{~nm}$ and $580 \mathrm{~nm}$.

Commercial phenolic compounds: Tannic acid and Mimosa extract were obtained from Sigma (France) and Silvateam (Italy), respectively Their molecular structures are given in Figures 3 and 4 respectively.

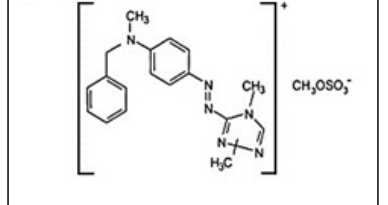

(A)

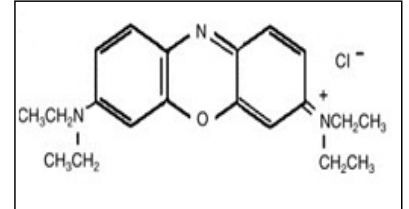

(B)

Figure 1: Chemical structure of studied basic dyes:(A) $\mathrm{Cl}$ Basic Red 46; (B) Cl Basic Blue 3.

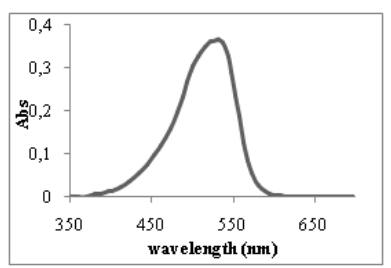

(A)

Figure 2: UV-vis spectra of basic dyes aqueous fraction (A): BR $46 \lambda \max =530$ $\mathrm{nm} ;(\mathrm{B}) \mathrm{BB} 3 \mathrm{\lambda max}=580 \mathrm{~nm}$<smiles>O=C(Oc1cc(O)c(O)c(O)c1)c1cc(OC(=O)c2cc(O)c(O)c(O)c2)cc(C(=O)OC2OC(OC(=O)c3cc(O)c(O)c(OC(=O)c4cc(O)c(O)c(O)c4)c3)C(OC(=O)c3cc(O)c(O)c(OC(=O)c4cc(O)c(O)c(O)c4)c3)C(OC(=O)c3cc(O)c(O)c(OC(=O)c4cc(O)c(O)c(O)c4)c3)C2OC(=O)c2cc(O)c(O)c(O)c2)c1</smiles>

Figure 3: Representation of tannic acid molecular structure.

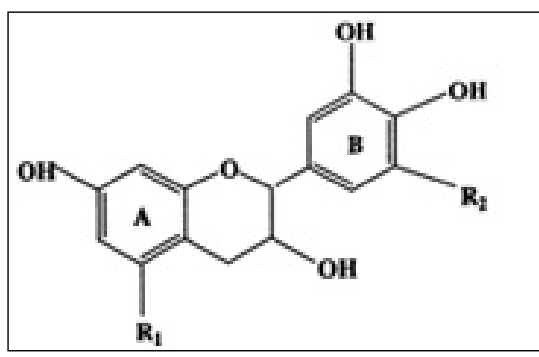

Figure 4: Molecular structure of Mimosa Tannin

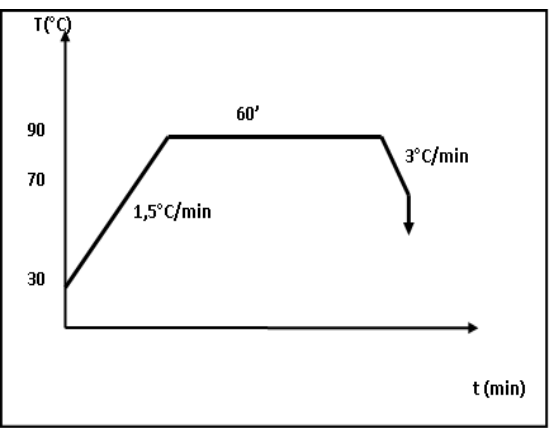

Figure 5: Dyeing process.

\begin{tabular}{|c|c|c|c|}
\hline & Clarite Com & Albatex & Albaflow \\
\hline Source & $\begin{array}{l}\text { Huntsman Textile } \\
\text { Effects (Germany) }\end{array}$ & $\begin{array}{l}\text { Huntsman Textile } \\
\text { Effects (Germany) }\end{array}$ & $\begin{array}{l}\text { Huntsman Textile } \\
\text { Effects (Germany) }\end{array}$ \\
\hline $\begin{array}{l}\text { Chemical } \\
\text { constitution }\end{array}$ & $\begin{array}{c}\text { Formulation of } \\
\text { nonionic surfactants } \\
\text { and phosphorus- } \\
\text { free dispersing } \\
\text { agents, without } \\
\text { APEO }\end{array}$ & $\begin{array}{l}\text { Mixture of an } \\
\text { additional } \\
\text { complexing agent } \\
\text { and polymers }\end{array}$ & $\begin{array}{c}\text { Preparation based } \\
\text { on a fatty alcohol } \\
\text { ethoxylate }\end{array}$ \\
\hline Ionic character & Anionic & Anionic & Anionic \\
\hline $\mathrm{pH}$ of $5 \%$ solution & 3,5 & 5 & 4,5 \\
\hline $\begin{array}{l}\text { Specificgravityat } \\
220^{\circ} \mathrm{C}\end{array}$ & About 1 & About 1.1 & About 1.0 \\
\hline Physicalform & Liquid & $\begin{array}{l}\text { Clear, colorless, } \\
\text { low-viscosity liquid }\end{array}$ & $\begin{array}{l}\text { White, medium- } \\
\text { viscosityliquid }\end{array}$ \\
\hline General Stability & \multicolumn{3}{|c|}{$\begin{array}{l}\text { Highly stable in hard water and to acids, alkalis and } \\
\text { electrolytes in the usual concentrations. }\end{array}$} \\
\hline Ecology/toxicology & \multicolumn{3}{|c|}{$\begin{array}{l}\text { The usual hygiene and safety rules for handling chemicals } \\
\text { should be observed in storage, handling and use. The product } \\
\text { must not beswallowed }\end{array}$} \\
\hline
\end{tabular}

Table 1: The properties of chemical modification agents

The prickly pear cactus cladodes were naturally collected in February 2012 from eastern Tunisian region. They were repeatedly washed with distilled water to remove thistles opuntia cactus and dirt particles and were sun dried for $3 \mathrm{~h}$, cutting into small pieces. The plant was then powdered using domestic mixer and dried at $60^{\circ} \mathrm{C}$ during $24 \mathrm{~h}$. The bio agent was stored in a glass bottle for further use agent without any pre-treatment.

Synthetic products such as Clarite Com, Albtex, Albaflow were supplied from (Huntsman Textile Effects, Germany). Their chemical properties were given in Table 1.

\section{Chemical modification of cellulosic fabrics}

The fabrics were treated with a solution containing different 
concentration of the modification agent at $50^{\circ} \mathrm{C}$ for $60 \mathrm{~min}$, keeping the material to liquor ratio at 40:1. Then, they were squeezed off to a liquor pick-up of $90 \%$ and dried.

\section{Dyeing process}

The fabrics were dyed at a liquor ratio of $40: 1$ in a dye bath containing $2 \%$ of cationic dye. The $\mathrm{pH}$ of dyeing bath is fixed at 5.5 . The dyeing was carried out in laboratory dyeing machine (Ahiba Datacolour International, USA) according to the process given in Figure 5. The dyed fabrics were then washed thoroughly with cold water and dried.

\section{Characterization of modified fabrics}

The Boehm titration method was applied to determine the surface functional groups containing oxygen. The main principle of this method is that oxygen groups on carbon surfaces have different acidities and can be neutralized by bases of different strength. Prior to the analysis, samples were dried at $110^{\circ} \mathrm{C}$ for $3 \mathrm{~h}$. Then, $0.5 \mathrm{~g}$ of each sample was added to glass bottles containing $25 \mathrm{ml}$ of the following 0.05 M solutions: $\mathrm{NaOH}, \mathrm{Na}_{2} \mathrm{CO}_{3}$ and $\mathrm{NaHCO}_{3}$. The bottles were sealed and shaken for $48 \mathrm{~h}$ to reach equilibrium. Then, the suspensions were filtered and $10 \mathrm{ml}$ of the filtrates were pipetted to $100 \mathrm{ml}$ Erlenmeyer flasks and the excess acid was back titrated with $0.05 \mathrm{M}$ standard solutions of $\mathrm{NaOH}$. The number of acidic sites was calculated assuming that $\mathrm{NaOH}$ neutralizes carboxylic, phenolic, and lactonic groups; $\mathrm{Na}_{2} \mathrm{CO}_{3}$ neutralizes carboxylic and lactonic groups, while $\mathrm{NaHCO}_{3}$ neutralizes carboxylic groups only [7].

The Point of Zero Charge (pHPZC) of the studied sample was determined using the $\mathrm{pH}$ drift method. A stepwise addition of $0.1 \mathrm{M}$ $\mathrm{HCl}$ and/or $0,1 \mathrm{M} \mathrm{NaOH}$ solutions were used for $\mathrm{pH}$ adjustment $(3,6$ and 9). $0.05 \mathrm{~g} ; 0.1 \mathrm{~g} ; 0.5 \mathrm{~g} ; 1 \mathrm{~g} ; 2.5 \mathrm{~g}$ and $5 \mathrm{~g}$ of each sample were added to $100 \mathrm{ml}$ of $\mathrm{NaCl}(0.1 \mathrm{M})$ at different $\mathrm{pH}$. These solutions were shaken for $24 \mathrm{~h}$. Then, the suspensions were filtered and we measured the $\mathrm{pH}$ of the solution. The curves of the $\mathrm{pH}$ evolution with the samples weights were represented. The Point of Zero Charge (pHPZC) is the average of the three $\mathrm{pH}$ values reached constant depending on the mass [8].

Fourier Transform Infrared (FTIR) spectra of the samples were recorded using a Schimatzu 8400 FTIR Spectrometer (Japan), with the processing software hyper 1.57 using potassium bromide disks. A total of 32 scans for each sample were taken with a resolution of $4 \mathrm{~cm}^{-1}$, with a range of 4000-400 $\mathrm{cm}^{-1}$.

\section{Measure of the bath exhaustion}

The dye bath exhaustion was determined spectrophotometrically. The absorbance of each dyebath solution was measured using a 1 $\mathrm{cm}$ path length quartz cell housed in an ultraviolet (UV)-2401 PC spectrophotometer (Schimadzu, Japan) both before and after the dying process at the maximum wavelength $\lambda$ max of cationic dye used.

The maximum wavelengths $\lambda$ max of the CI BR 46 and CI BB3 were found to be respectively $530 \mathrm{~nm}$ and $580 \mathrm{~nm}$. The bath exhaustion percentage $\mathrm{E}$ (\%) was calculated according to the following equation:

$$
E(\%)=\frac{\left(A_{0}-A_{r}\right)}{A_{0}} \times 100
$$

Where $\mathrm{A}_{0}$ and $\mathrm{A}_{\mathrm{r}}$ are, respectively, the absorbance of the dyeing bath before and after dyeing.

\section{Colour evaluation}

Colour values such as $\mathrm{L}^{\star}, \mathrm{a}^{\star}, \mathrm{b}^{\star}$ and K/S were measured by Spectro Flash SF300 spectrophotometer with data Master 2.3 (Datacolor
International, USA) using D65 and $10^{\circ}$ standard observer. $\mathrm{L}^{*}, \mathrm{a}^{*}$ and $\mathrm{b}^{\star}$ represent lightness or luminosity, redness-greenness of colour and yellowness-blueness of colour, respectively. The colour yield $(\mathrm{K} / \mathrm{S})$ value was measured at $\lambda \max$ and transferred to $(K / S)$ according to the Kubelka-Munk equation $[9,10]$.

Where $\mathrm{R}$ is the decimal fraction of the reflectance of dyed fabric, $\mathrm{R}_{0}$ is the decimal fraction of the reflectance of undyed fabric, $\mathrm{K}$ is the absorption coefficient and $\mathrm{S}$ is the scattering coefficient.

\section{Measure of Brightness Index (BI)}

Brightness index was calculated using the following formula (ISO 2470-1: 2009):

Where $\mathrm{BI}(\%)$ is the brightness index, $\mathrm{R}_{\mathrm{s}}$ is the reflectance value of the substrate at $457 \mathrm{~nm}$ and $\mathrm{R}_{\mathrm{s}} \mathrm{d}$ is the reflectance value of the standard diffuser/white at $457 \mathrm{~nm}$.

\section{Fastness testing}

The dyed samples were tested according to ISO standard methods. The specific tests were for colour fastness to washing ISO 105-C06:2010, colour fastness to rubbing ISO 105-F09:2009 and colour fastness to light ISO 105-B02:1999.

\section{Results and Discussion}

\section{Absorbance of the dyestuffs}

Figure 2 shows respectively the UV-vis spectrum of the basic Red 46 and the basic blue 3 aqueous fraction. It was found that these spectrums showed two major peaks respectively in the visible region at 530 and $585 \mathrm{~nm}$.

\section{Effect on the extent of the dye bath exhaustion and the color yield $(\mathrm{k} / \mathrm{s})$}

For the different modification reagent, the effects of this variation on the evolution of the dye bath exhaustion are represented in Figures 6 and 7 and the effects of this variation on the evolution of the color yield are represented in Figures 8 and 9.

In the aim to evaluate the effectiveness of cellulosic fibers modification in dyeing cotton and jute, the dye bath exhaustion and the color yield were studied for different dose of modification reagent. Figures 6-9 clearly showed the pronounced cellulosic modification

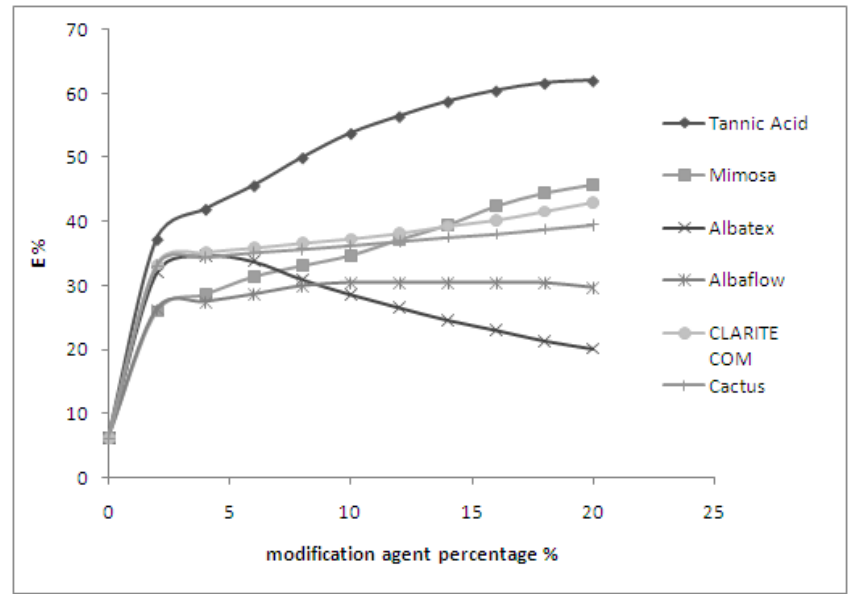

Figure 6: The effect on the extent dye bath exhaustion (for cotton). 


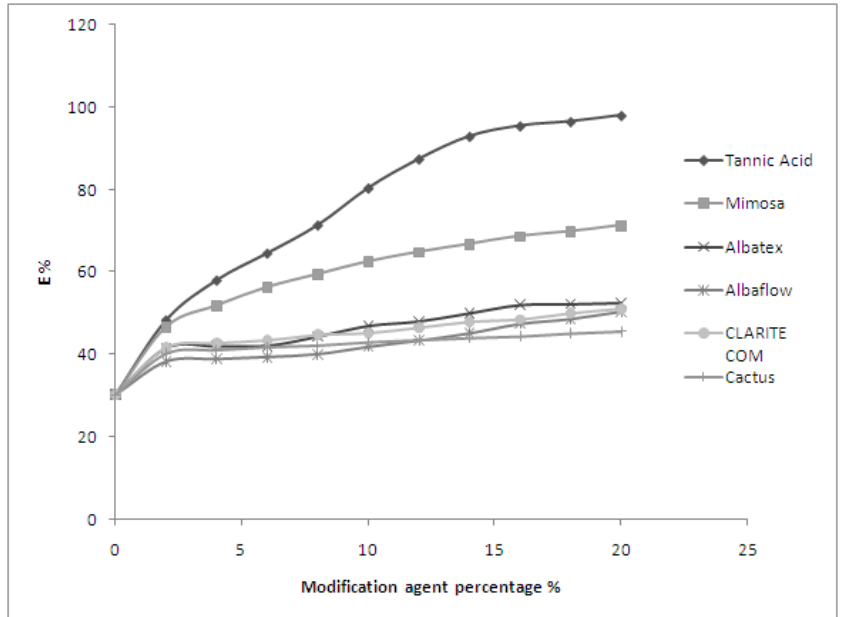

Figure 7: The effect on the extent dye bath exhaustion (for jute).

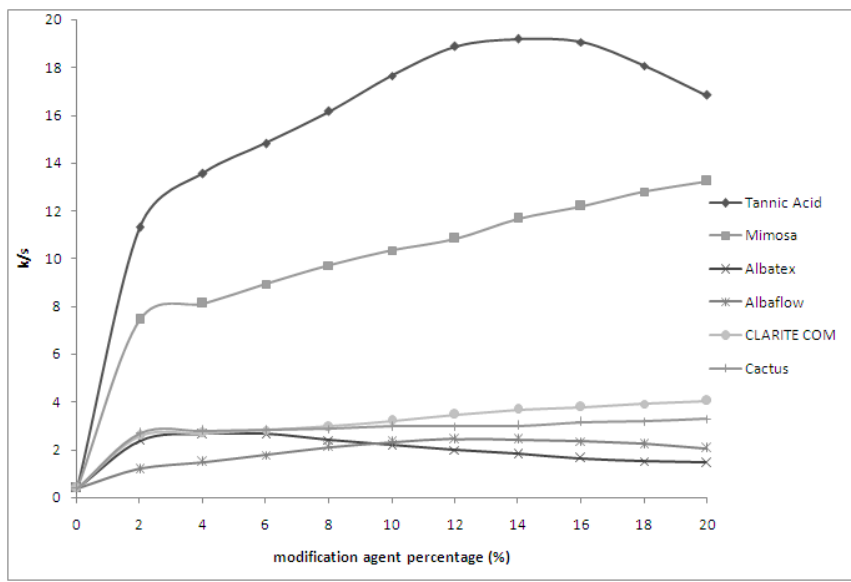

Figure 8: The effect on the color yield (for cotton).

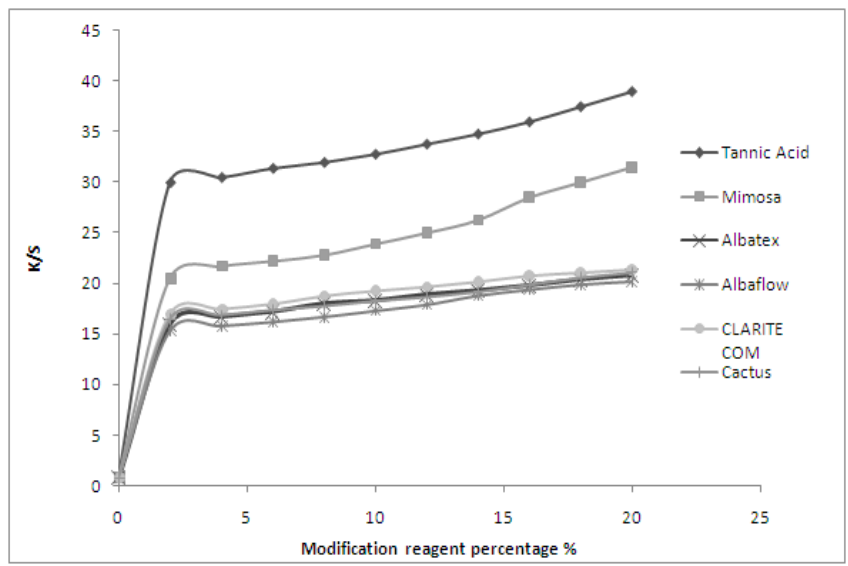

Figure 9: The effect on the color yield (for jute).

enhancement respectively in the dye bath exhaustion and the color yield for cotton and jute samples for cotton and jute samples.

Tannic Acid, Mimosa, Cactus extract are natural modification reagent. Clarite Com, Albatex and Albaflow are commercial anionic agents. They were applied in the preparation step at different concentration going from $0 \%$ to $20 \%$ (w/w with respect to the fabric) in order to select the best modification agent for cotton and jute fabrics.

Thus, the modified samples were then dyed with Basic Red 46 (cationic dye) using the exhausting process as described in the experimental part. The quality of this dyeing was evaluated by measuring the dye bath exhaustion (E \%) and the color yield (k/s).

The obtained results reveal that all the curves representing the evolution of the dye bath exhaustion and the color yield with the amount of the modification agent have nearly the same shape for the cotton and the jute samples.

The dye bath exhaustion and the color yield for various modification reagents were maximum for the tannic acid, then for the mimosa. Graphical data show a continuous improvement in the dye bath exhaustion and k/s after modification (respectively $60 \%$ and for tannic acid). It increases with increasing the modification reagent dose. These results were obtained for the cotton and the jute fabrics.

Moreover, $\mathrm{k} / \mathrm{s}$ values for various modification reagents were maximum for the tannic acid, then for the mimosa. These results were obtained for cotton and jute fibers.

In this part, the color yield remained quasi stable. It seems here that the modified cellulosic fibres reached the absorption saturation of the cationic dye. Figures 8 and 9 show also that whatever the modification agent is used in the preparation step, modified cotton leaded to a better quality of dyeing compared to the untreated cotton. In fact, in the absence of modification agent, the recorded color yield $(\mathrm{k} / \mathrm{s})$ was equal to 0.4 which is lower than those obtained when using modification treatment. However, it can be seen in Figures 8 and 9 that this increase of color yield varies from one modification agent to another.

Indeed, Basic dyes have no direct affinity for cellulose but jute fibers processes good affinity for basic dyes due to the presence of lignin $(12 \%)$ and hemicelluloses containing peripheral $-\mathrm{COOH}$ in the fibers and require no mordanting prior to dyeing. Their tinctorial power is very high. But from the practice, it has light fastness on jute.

The $(\mathrm{k} / \mathrm{s})$ values of the different modified samples increased in the following order: Tannic acid $>$ Mimosa $>$ Clarite Com $>$ Cactus $>$ Albatex $>$ Albaflow.

\section{The effect on the CIELab coordinates}

For the different modification reagent, the effects of this variation on the evolution on the CIELab coordinates are represented in Tables 2 and 3.

The luminosity decreased with the increasing of the concentration of modification reagent. It was minimal for the modification with tannic acid and mimosa. The parameters $\mathrm{a}^{*}$ and $\mathrm{b}^{*}$ increased also with the increasing of the modification reagent dose and the shade became redder and yellower, respectively.

\section{The effect on the Brightness Index (BI \%)}

The percentage of the modification agent was varied between 0 and $20 \%$ (w/w with respect to the fabric), and the evolution of the bath exhaustion E (\%), the color yield (K/S), as well as the brightness index BI (\%) were studied. The results are presented in Figures 10 and 11.

From these figures, it can be seen that the exhaustion bath and the brightness index obtained are ameliorated when using modified cotton and jute and remain quasi stable for a modification agent percentage of 
Citation: Bouatay F, Meksi N, Slah F, Mohamed FM (2014) Chemical Modification of Cellulosic Fibers Using Eco-Friendly Compounds to Improve Dyeing with Cationic Dyes. J Textile Sci Eng 4: 153. doi:10.4172/2165-8064.1000153

Page 5 of 8

\begin{tabular}{|l|c|c|c|c|c|}
\hline Cotton samples & $\mathbf{L}^{*}$ & $\mathbf{a}^{*}$ & $\mathbf{b}^{*}$ & $\mathbf{h}$ & $\mathbf{C}$ \\
\hline Bleached Cotton & 75.42 & 16.5 & -5 & 334 & 17.2 \\
\hline Tannicacid & 36.34 & 52.29 & 2.15 & 356.22 & 52.57 \\
\hline Mimosa & 37.31 & 48.68 & 0.95 & 355.14 & 43.09 \\
\hline CLARITE COM & 55.28 & 44.91 & -2.8 & 355.34 & 45.04 \\
\hline Cactus & 55.63 & 44.7 & -2.7 & 355.3 & 44.4 \\
\hline Albatex & 61.19 & 35.46 & -2.43 & 355.41 & 38.09 \\
\hline Albaflow & 64.87 & 34.2 & -3.23 & 355.91 & 32.02 \\
\hline
\end{tabular}

Table 2: The CIELab coordinates of cotton fabrics dyed with CI Basic Red 46.

\begin{tabular}{|l|c|c|c|c|c|}
\hline Jutesamples & $\mathbf{L}^{*}$ & $\mathbf{a}^{*}$ & $\mathbf{b}^{*}$ & $\mathbf{h}$ & $\mathbf{c}$ \\
\hline Bleachedjute & 34.6 & 48 & 11.1 & 355 & 30 \\
\hline Tannicacid & 14.6 & 62 & 38.3 & 359 & 34 \\
\hline Mimosa & 23.1 & 56 & 23.2 & 359 & 44.4 \\
\hline CLARITE COM & 28 & 52.9 & 17.41 & 358 & 52.4 \\
\hline Cactus & 28.3 & 52.8 & 16.9 & 358 & 52.1 \\
\hline Albatex & 28.5 & 52.7 & 16.3 & 358 & 51.4 \\
\hline Albaflow & 29 & 52.6 & 15.6 & 358 & 50.3 \\
\hline
\end{tabular}

Table 3: The CIELab coordinates of jute fabrics dyed with CI Basic Red 46.

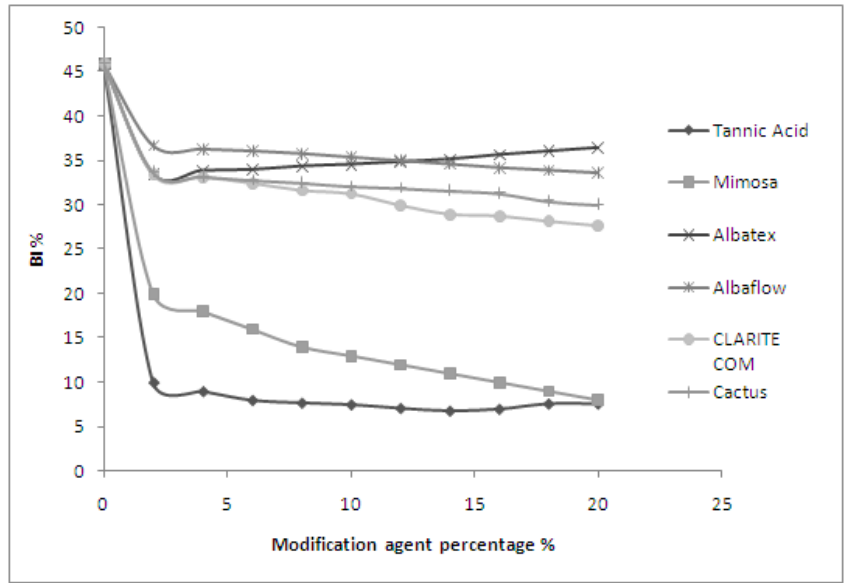

Figure 10: The effect on the Brightness Index (BI\%) (for cotton).

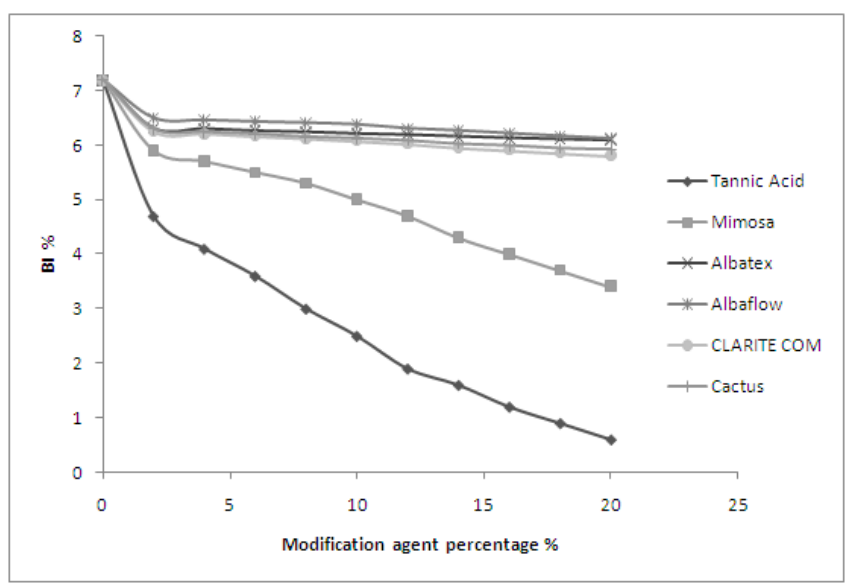

Figure 11: The effect on the Brightness Index (BI\%) (for jute).

$10 \%$ and more. These results show that the brightness index depends closely on the evolution of the color yield and the exhaustion bath. The increase of the brightness index can be explained by the increase of the amount of absorbed cationic dye. This dye is characterized by good brightness properties. However, it can be also observed that the experimental values of the bath Exhaustion, E (\%), the color yield (K/S) and the Brightness Index, BI (\%) remained inferior to those obtained with untreated cotton and jute dyed by the cationic dye (CI Basic red 46).

\section{The effect on fastness properties of dyed fabrics}

The rating of fastness (light, washing and rubbing fastness) of cellulosic fabrics dyed with Basic Red 46 is shown in Tables 4 and 5.

It was found that water and rubbing fastness of modified fabrics were considerably good. This result can be attributed to the high affinity of cationic dye. However, the light fastness of bleached cotton and jute were poor and will be good for the modified cotton and jute fabrics. Generally, it is well known that the poor light fastness was a problem for cationic dyes.

Despite of the highly sensitive of lignin to the action of light [6], modified jute has a good light fastness thanks to anionic groups and the terminal groups of hemicelluloses able to fixe cationic dyes.

\section{Dyeing with CI basic blue 3}

In the second part, we study the affinity of cotton and jute fibers on the CI Basic Blue 3. Surfaces modifications were performed on cellulosic samples used in this part with $20 \%$ (w/w with respect to the fabric) of modification agent. The dyeing properties of cotton and jute fabrics dyed with CI Basic Blue 3 were given respectively in Tables 6 and 7 . The color and the dyeing experiences in all cases were evaluated

\begin{tabular}{|l|c|c|c|c|}
\hline Cotton fabrics & Wash ISO & Light ISO & \multicolumn{2}{|c|}{ Rubbing ISO 105-F09 } \\
\cline { 4 - 5 } & $\mathbf{1 0 5 - C 0 6}$ & 105-B02 & Dry & Wet \\
\hline Bleachedcotton & $2-3$ & $1-2$ & $2-3$ & $1-2$ \\
\hline TannicAcid & $4-5$ & $3-4$ & 4 & $2-3$ \\
\hline Mimosa & 4 & $3-4$ & 4 & $2-3$ \\
\hline Clarite Com & 3 & 3 & 3 & 2 \\
\hline Cactus juice & 3 & 3 & 3 & 2 \\
\hline Albtex & 3 & 3 & 3 & 2 \\
\hline Albaflow & 3 & $2-3$ & 3 & 2 \\
\hline
\end{tabular}

Table 4: Fastness properties of cotton dyed fabrics with $\mathrm{Cl}$ Basic Red 46.

\begin{tabular}{|l|c|c|c|c|}
\hline Jutefabrics & Wash ISO & Light ISO & \multicolumn{2}{|c|}{ RubbingISO 105-F09 } \\
\cline { 4 - 5 } & 105-C06 & 105-B02 & Dry & Wet \\
\hline Bleachedjute & 3 & $1-2$ & 3 & 2 \\
\hline TannicAcid & $4-5$ & $3-4$ & $4-5$ & $3-4$ \\
\hline Mimosa & $4-5$ & $3-4$ & $4-5$ & 3 \\
\hline Clarite Com & $3-4$ & 3 & $3-4$ & $2-3$ \\
\hline Cactus juice & $3-4$ & 3 & $3-4$ & $2-3$ \\
\hline Albtex & $3-4$ & 3 & $3-4$ & $2-3$ \\
\hline Albaflow & $3-4$ & 3 & $3-4$ & $2-3$ \\
\hline
\end{tabular}

Table 5: Fastness properties of jute dyed fabrics with Cl Basic Red 46.

\begin{tabular}{|l|l|l|l|l|l|l|l|}
\hline Cottonsamples & E\% & K/S & L* $^{*}$ & $\mathbf{a}^{*}$ & $\mathbf{b}^{*}$ & h & $\mathbf{c}$ \\
\hline Bleachedcotton & $6.8 \%$ & 0.37 & 75.1 & -5.7 & 30.4 & 254.5 & 23.4 \\
\hline Tannicacid & $61.2 \%$ & 19.13 & 39.3 & -4.7 & 23.15 & 257.4 & 27.5 \\
\hline Mimosa & $47.3 \%$ & 17.2 & 40.6 & -4.9 & 24.4 & 256.9 & 26.8 \\
\hline CLARITE COM & $44.5 \%$ & 3.8 & 56.4 & -5.15 & 26.3 & 257.3 & 25.1 \\
\hline Cactus & $39.6 \%$ & 3.6 & 56.9 & -5.2 & 26.8 & 256 & 24.9 \\
\hline Albatex & $20.1 \%$ & 1.7 & 58.4 & -5.6 & 28.5 & 256.4 & 24.8 \\
\hline Albaflow & $29.2 \%$ & 1.8 & 58.9 & -5.5 & 28.3 & 257.8 & 24.7 \\
\hline
\end{tabular}

Table 6: The dyeing properties for cotton samples dyed with $\mathrm{Cl}$ Basic Blue 3. 
Citation: Bouatay F, Meksi N, Slah F, Mohamed FM (2014) Chemical Modification of Cellulosic Fibers Using Eco-Friendly Compounds to Improve Dyeing with Cationic Dyes. J Textile Sci Eng 4: 153. doi:10.4172/2165-8064.1000153

Page 6 of 8

\begin{tabular}{|l|l|l|l|l|l|l|l|}
\hline Jutesamples & E\% & K/S & $\mathbf{L}^{*}$ & $\mathbf{a}^{*}$ & $\mathbf{b}^{*}$ & $\mathbf{h}$ & $\mathbf{C}$ \\
\hline Bleachedjute & $30.3 \%$ & 0.7 & 33.9 & -4.6 & 23.1 & 28.7 & 255.2 \\
\hline Tannicacid & $95.6 \%$ & 38.4 & 16.3 & -3.7 & 19.6 & 30.5 & 257.4 \\
\hline Mimosa & $72.4 \%$ & 31.6 & 24.4 & -3.8 & 19.9 & 29.8 & 256.5 \\
\hline CLARITE COM & $48.2 \%$ & 22.3 & 29.3 & -3.9 & 20.6 & 28.3 & 257.7 \\
\hline Cactus & $41 \%$ & 21.5 & 29.9 & -3.9 & 20.7 & 28.1 & 258.2 \\
\hline Albatex & $49.6 \%$ & 21 & 30.5 & -4 & 21.8 & 28 & 257.3 \\
\hline Albaflow & $48 \%$ & 20.8 & 31.8 & -4.1 & 21.7 & 28.1 & 257.8 \\
\hline
\end{tabular}

Table 7: The dyeing properties for jute samples dyed with $\mathrm{Cl}$ Basic Blue 3.

\begin{tabular}{|l|c|c|c|c|}
\hline Cotton fabrics & Wash ISO & Light ISO & \multicolumn{2}{|c|}{ RubbingISO 105-F09 } \\
\cline { 4 - 5 } & 105-C06 & 105-B02 & Dry & Wet \\
\hline Bleachedcotton & $2-3$ & $1-2$ & $2-3$ & $1-2$ \\
\hline TannicAcid & $4-5$ & $3-4$ & 4 & $2-3$ \\
\hline Mimosa & 4 & $3-4$ & 4 & $2-3$ \\
\hline Clarite Com & 3 & 3 & 3 & 2 \\
\hline Cactus juice & 3 & 3 & 3 & 2 \\
\hline Albtex & 3 & 3 & 3 & 2 \\
\hline Albaflow & 3 & $2-3$ & 3 & 2 \\
\hline
\end{tabular}

Table 8: Fastness properties of cotton dyed samples (CI BB3).

\begin{tabular}{|l|c|c|c|c|}
\hline Jutefabrics & Wash ISO & Light ISO & \multicolumn{2}{|c|}{ RubbingISO 105-F09 } \\
\cline { 4 - 5 } & $\mathbf{1 0 5 - C 0 6}$ & 105-B02 & Dry & Wet \\
\hline Bleachedjute & 3 & $1-2$ & 3 & 2 \\
\hline TannicAcid & $4-5$ & $3-4$ & $4-5$ & $3-4$ \\
\hline Mimosa & $4-5$ & $3-4$ & $4-5$ & 3 \\
\hline Clarite Com & $3-4$ & 3 & $3-4$ & $2-3$ \\
\hline Cactus juice & $3-4$ & 3 & $3-4$ & $2-3$ \\
\hline Albtex & $3-4$ & 3 & $3-4$ & $2-3$ \\
\hline Albaflow & $3-4$ & 3 & $3-4$ & $2-3$ \\
\hline
\end{tabular}

Table 9: Fastness properties of jute samples (CI BB3).

\begin{tabular}{|l|c|c|c|c|}
\hline Jutefabrics & $\begin{array}{c}\text { Carboxylic } \\
(\mathbf{1 0} / \mathbf{g})\end{array}$ & $\begin{array}{c}\text { Lactonic } \\
\mathbf{( 1 0 ^ { 2 0 } / \mathbf { g } )}\end{array}$ & $\begin{array}{c}\text { Phenolic } \\
\left.\mathbf{( 1 0 ^ { 2 0 }} / \mathbf{g}\right)\end{array}$ & $\begin{array}{c}\text { Number of } \\
\text { acidic Sites } \\
\mathbf{( 1 0 ^ { 2 0 }} \mathbf{g} \mathbf{)}\end{array}$ \\
\hline Tannicacid & 8,998 & 7,681 & 10,393 & 27,072 \\
\hline Mimosa & 6,853 & 4,141 & 9,313 & 20,307 \\
\hline Clarite & 8,43 & 5,422 & 5,74 & 19,592 \\
\hline Cactus & 8,26 & 3,22 & 7,8 & 19,28 \\
\hline Albatex & 6,998 & 7,23 & 4,313 & 18,541 \\
\hline Albaflow & 8,435 & 4,73 & 3,753 & 16,918 \\
\hline Albaflow & $3-4$ & 3 & $3-4$ & $2-3$ \\
\hline
\end{tabular}

Table 10: Acidic Sites of modified cotton samples.

by means of color yield (K/S), the extent of exhaustion as well as the CIELab Coordinates and the corresponding fastness properties were also determined.

The dye bath exhaustion, the color yield and the CIELab coordinates obtained with the CI Basic Blue 3 are akin those obtained for the CI Basic Red 46. The dye bath exhaustion and the color increase for the modified samples. From these results, we can generalize the efficiency of the modification with the previous agent on the Dyeing with cationic dye.The fastness properties are ameliorated after modification. The evolution of the rating of fastness (light, washing and rubbing) was also investigated when we use modification agent. The results are summarized in Tables 8 and 9. It was found that the studied dyeing fastness were improved when cotton and jute was modified.

\section{Bohem titration}

Table 10 summarized the results of Boehm titration. The number of acidic sites was the sum of the acidic functional groups: carboxylic, lactonic and phenolic groups. The cotton fabric modified by tannic acid presented the highest number of acidic sites $\left(27,027^{\star} 1020\right)$, then Mimosa $\left(20,307^{\star} 1020\right)$ followed by Clarite $\left(19,592^{\star} 1020\right)$ and Cactus juice $\left(19,28^{\star} 1020\right)$.

N. Barka [11] showed that the cactus juice presented carboxylic and phenolic groups. This result was confirmed by Bohem Titration of cotton samples treated by Cactus juice before dying.

\section{CEC and Point of Zero Charge (PZC)}

The Cation Exchange Capacity (CEC) values were given in Table 11. The CEC vary from $15 \mathrm{meq} / \mathrm{g}$ to $15,6 \mathrm{meq} / \mathrm{g}$. The lowest CEC was obtained for the raw clay (S1). The $\mathrm{pH}$ at which the total particle charge is zero is called the Point of Zero Charge (PZC), which is one of the most important parameters used to describe variable-charge surfaces [12-14].

The Point of Zero Charge (PZC), in physical chemistry, is a concept relating to the phenomenon of adsorption, and it describes the condition when the electrical charge density on a surface is zero [15-18].

When the $\mathrm{pH}$ is lower than the PZC value, the system is said to be "below the PZC." Below the PZC, the acidic water donates more protons than hydroxide groups, and so the adsorbent surface is positively charged (attracting anions). Conversely, above PZC the surface is negatively charged (attracting cations/repelling anions).

The PZC was measured for the cellulosic fibers treated with $20 \%$ of modification reagent. The results are presented in Figures 12 and 13.

The PZC characterized the acidity or the alkalinity of the surface. A pH lower than the PZC, the surface charge was positive (acidity) and a $\mathrm{pH}$ higher than the $\mathrm{PZC}$, the surface charge was negative (alkalinity) and tends to decrease.

The pHi of the dye bath was about 5.5. So the bleached cotton has a low value of $\Delta \mathrm{P}=\llbracket \mathrm{pH} \rrbracket \_\mathrm{i}$ - PZC so the samples had a poor affinity to the cationic dye. After the modification the $\mathrm{PZC}$ decreases and the $\mathrm{pHi}$

\begin{tabular}{|l|c|c|}
\hline & PZC & CEC (meq/g) \\
\hline Bleachedcotton & 5,4 & 58 \\
\hline Tannicacid & 3,45 & 36 \\
\hline Mimosa & 3,84 & 38 \\
\hline Clarite & 4,2 & 43 \\
\hline Cactus & 4,5 & 45 \\
\hline Albatex & 4,9 & 48 \\
\hline Albaflow & 4,9 & 49 \\
\hline
\end{tabular}

Table 11: PZC and CEC of the cotton samples.

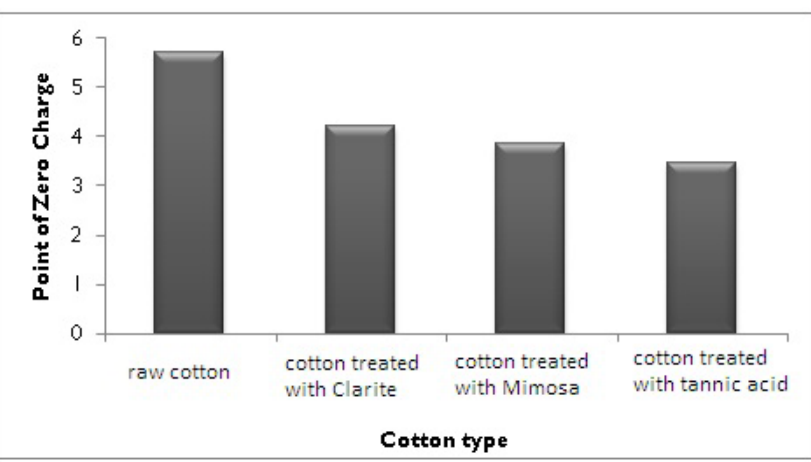

Figure 12: The PZC of the modified cotton. 


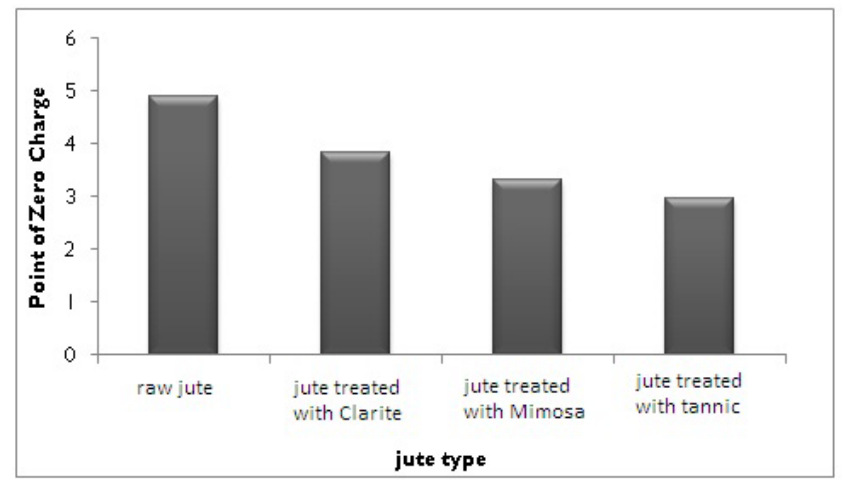

Figure 13: The PZC of the modified jute.

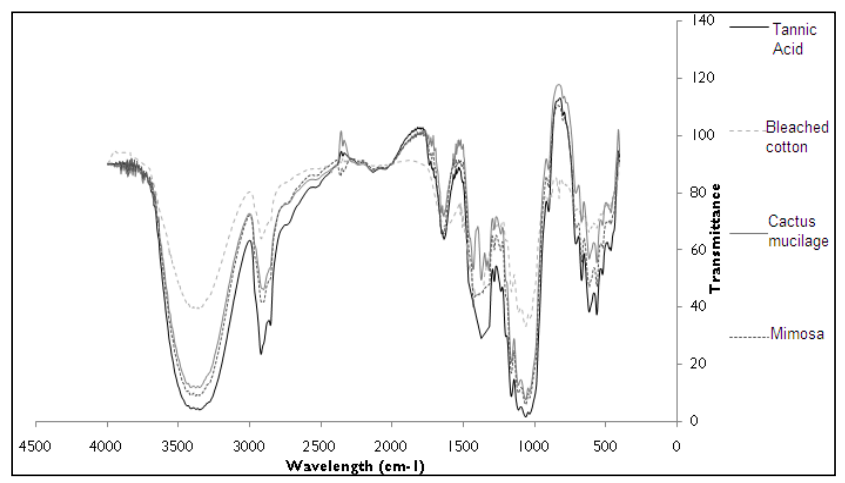

Figure 14: FTIR spectrum (KBr) of cotton fabrics

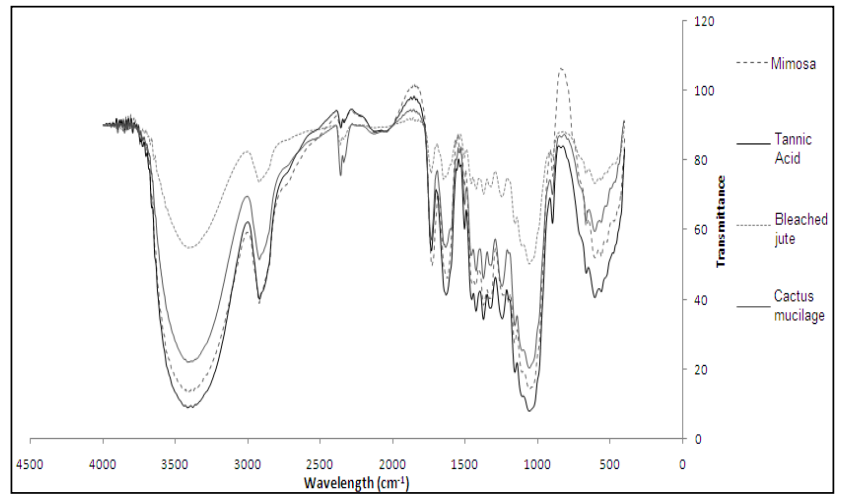

Figure 15: FTIR spectrum (KBr) of jute Fabrics.

was always higher than the PZC so the surface of the cellulose becomes negative and the affinity to the cationic dyes decrease.The tannic acid has the lowest PZC, so the surface of the modified sample was the most negative, so the color yield and the fastness properties were maximal. Adsorption of tannic acid on the cellulosic surface occurred due to electrostatic interactions and hydrogen interactions formed between the terminal carboxyl groups of the cellulose and phenolic hydroxyl groups of tannic acid.

\section{Fourier Transform Infrared Spectroscopic Analysis (FTIR)}

Fourier-transform infrared spectra were used to identify the presence of functional groups on the solid surface of the modified cotton. Figures 14 and 15 show FT-IR spectra of untreated and modified cotton and jute by $20 \%$ modified agent. FT-IR spectra of all samples showed characteristic cellulose peaks around 1000-1200 $\mathrm{cm}^{-1}$. Other characteristic bands related to the chemical structure of cellulose were the hydrogen-bonded $\mathrm{O}-\mathrm{H}$ stretching at $3550-3100 \mathrm{~cm}^{-1}$, the $\mathrm{C}-\mathrm{H}$ stretching at $2917 \mathrm{~cm}^{-1}$, and the $\mathrm{C}-\mathrm{H}$ wagging at $1385 \mathrm{~cm}^{-1}$.

The broad peaks centred at $3420 \mathrm{~cm}^{-1}$ corresponding to $\mathrm{O}-\mathrm{H}$ stretching, the peak at $3000-2800 \mathrm{~cm}^{-1}$ region for $\mathrm{C}-\mathrm{H}$ stretching and the peak at $2917 \mathrm{~cm}^{-1}$ corresponding to the $\mathrm{C}-\mathrm{H}$ stretching increase after the modification and became more important. Although cellulose contains $-\mathrm{CH}_{2}-$ groups in their structure, the peaks corresponding to the symmetric and asymmetric stretching modes have never been separated as sharp peaks. A peak around $1648 \mathrm{~cm}^{-1}$ is due to the adsorbed water molecules.

\section{Conclusion}

In this study, we improve the affinity of cotton and jute fibres to the cationic dyes. Surface modifications were performed on cellulose samples used in this work by different chemical products. An InfraRed (IR) spectroscopy was studied to compare these cellulosic fibres modifications. The colour in all cases was evaluated after the dyeing by means of colour yield (K/S), the extent of exhaution as well as the CIELab coordinates and the corresponding fastness properties were also determined. These analyses showed that the dye ability of the cellulosic fibers (cotton and jute) with the cationic dye increase after modification. Based on the above research, it is obvious that higher dyeing quality (color yield $(\mathrm{K} / \mathrm{S}$ ) increase from 0,37 to 3,6 after modification with cactus juice of cotton fabrics) and fastness properties could be achieved on the modified cotton and jute compared to the one obtained on untreated fabrics.

\section{References}

1. Mirjalili M, Nazarpoor K, Karimi L (2011) Eco-friendly dyeing of wool using natural dye from weld as co-partner with synthetic dye. J Clean Prod 19: 10451051.

2. Dhodapkar R, Rao NN, Pande SP, Kaul SN (2006) Removal of basic dyes from aqueous medium using a novel polymer: Jalshakti. Bioresour Technol 97: 877-885.

3. Tae-Kyung K, Seok-Han Y, Young-AS (2003) Effect of reactive anionic agent on dyeing of cellulosic fibers with a Berberine colorant. Dyes and Pigments 60: $121-127$

4. Arthur DB (2001) Basic principles of Textile Coloration. Society of Dyers and Colourists, Canada.

5. Ontiveros-Ortega, Espinosa-Jime'nez ME, Chibowski F, lez-Caballero G (1998) Effect of Tannic Acid on the Surface Free Energy of Cotton Fabric Dyed with a Cationic Dye. Colloid Interface Sci 202: 189-194.

6. Salam MA (2005)Study of the color fastness properties onto bleached sulfonated jute-cotton blended fabrics with basic dyes. J Textile Appl Tech Manag 4: 1-6.

7. Milan M, Purenović M, Bojić A, Zarubica A, Ranđelović M (2011) Removal of lead(II) ions from aqueous solutions by adsorption onto pine cone activated carbon. Desalination 276: 53-59.

8. Joong SN, James AS (1990) Effect of $\mathrm{HNO}_{3}$ treatment on the surface acidity of activated carbons. Carbon 28: 675-682.

9. Kubelka PK (1948) New contributions to the optics of intensely light-scattering materials. J Opt Soc Am 38: 448-457.

10. Kubelka PK (1954) New contributions to the optics of intensely light-scattering materials. Part II. Nonhomogeneous layers. J Opt Soc Am 44: 330-334.

11. Barka N,Abdennouri M, El-Makhfouk M, Qourzal S (2013) Biosorption characteristics of cadmium and lead onto eco-friendly dried cactus (Opuntiaficusindica) cladodes. J Environ Chem Engg 3: 144-149. 
Citation: Bouatay F, Meksi N, Slah F, Mohamed FM (2014) Chemical Modification of Cellulosic Fibers Using Eco-Friendly Compounds to Improve Dyeing with Cationic Dyes. J Textile Sci Eng 4: 153. doi:10.4172/2165-8064.1000153

Page 8 of 8

12. Al-Degs Y, Khraisheh MA, Allen SJ, Ahmad MN (2000) Effect of carbon surface chemistry on the removal of reactive dyes from textile effluent. Water Res 34 : 927-935

13. Moreno-Castilla C (2004) Adsorption of organic molecules from aqueous solutions on carbon materials. Carbon 42: 83-94

14. Nabais JM, Laginhas CE, Carrot PJ, Carrot R (2011) Production of activated carbons from almond shell. Fuel Proc Tech 92: 234-240.
15. Hunter RJ (1989) Foundations of Colloid Science. Oxford University Press, UK.

16. Kirby BJ (2010) Micro- and Nanoscale Fluid Mechanics: Transport in Microfluidic Devices. Cambridge University Press, UK.

17. Lyklema J (1995) Fundamentals of Interface and Colloid Science. Academic Press, USA.

18. Russel WB, Saville DA, Schowalter WR (1992) Colloidal Dispersions Cambridge University Press, UK. 